\title{
HISTORIOGRAFIA DAS FORMAS FAMILIARES. DILEMAS E ENCRUZILHADAS*
}

\author{
Historiography of family forms. \\ Dilemmas and crossroads \\ Ricardo Cicerchia $^{* *}$
}

\begin{abstract}
RESUMO
Sobre este itinerário científico dos estudos de família, ainda inconcluso, nos propusemos desenvolver duas questões aparentemente ingênuas para a história de família. Em que sentido podemos dizer que a família tem história? E em que sentido a família europeia, inspiradora dos modelos clássicos de análise, se diferencia das do resto do mundo? Trata-se de certa necessidade de voltar aos fundamentos da história e à antropologia, duas disciplinas que contribuíram muito ao imaginário social sobre a família, de retomar seus encontros e acalmar os desvelos que geram certas confusões conceituais. A tais efeitos será exposta a questão de um itinerário americano para o campo, bem como dos problemas residenciais e a organização social da cotidianidade. Por outro lado, aludir-se-á a sete recorrências fundamentais, a saber: reafirmar o caráter patriarcal e o impacto decisivo da lógica econômica do capitalismo sobre a organização familiar; revisitar a hermenêutica da "razão familiar"; reinterpretar as práticas familiares como expressão de um sistema cultural; repensar o casamento e a moradia como um problema; compreender o desafio proposto pelo padrão linguístico à narrativa histórica; reorientar os novos lineamentos da pesquisa sobre os tipos e intensidades da pobreza, e propor uma estética das formas familiares que historie o imaginário social.
\end{abstract}

Palavras-chave: história da família; performances familiares; formas familiares americanas.

*Artigo traduzido por Sebastião Lourenço dos Santos.

"* Doutor em História Latino-Americana pela Columbia University, professor titular de História Latino-Americana na Universidade de Buenos Aires, Pesquisador do "Consejo Nacional de Investigaciones Científicas y Técnicas" (CONICET), República Argentina. 


\begin{abstract}
On the basis of this scientific itinerary without any definitive conclusion, we propose to develop two questions apparently naive to the family history. In what sense can we talk about the history of the family? And in what sense the European family, base for almost all the classic analysis models, is different to the rest of the world? For this goal, we propose to back to certain fundaments of history and anthropology, two of the most important fields for the social imaginary of family, to understand its encounters, and answer a set of conceptual confusions coming from recent works. In order to do so, we will present the question of an American itinerary for the field, as well as residential arrangements and the social organization of daily life. Moreover, we will address seven fundamental itineraries: reaffirming the patriarchal character and decisive impact of the capitalist economic logic on family organization; revisiting the hermeneutics of the 'family reason'; reinterpreting family practices as expression of a cultural system; reconsidering marriage and housing as a problem; reorientating the new research guidelines about the types and intensities of poverty and proposing an aesthetic of family forms that historizes the social imaginary.

Key-words: family history; family performances; American family forms.
\end{abstract}

A família (sujeito histórico) é um acontecimento demográfico, econômico, jurídico e, fundamentalmente, um conjunto de vínculos humanos, ou seja, cultural ${ }^{1}$. É justamente esta diversidade que determina a posição estratégica da história dentro das ciências sociais. A família é uma organização social que contém intrinsecamente mudanças e tradição,

1 Algumas conclusões preliminares, produto de vários anos de pesquisa compartilhados entre Buenos Aires e Barcelona, foram apresentadas no "Foro Internacional sobre el Nexo entre Ciencias Sociales y Políticas" patrocinado pela UNESCO (Universidad Nacional de Córdoba, Argentina, 2006) e em seguida publicadas em: CICERCHIA, R.; BESTARD, J. ¡Todavía una historia de la familia! Encrucijadas e itinerarios en los estudios sobre las formas familiares. Revista Latinoamericana de Ciencias Sociales, Niñez y Juventud. Manizales, Colombia, v. 4, n. 1, p. 17-37, 2006. Também uma versão preliminar deste ensaio foi exposta no Congreso Internacional "Familia y Organización Social en Europa y América, Siglos XV-XX", Murcia-Albacete, España, 2007. Para esta última versão meu reconhecimento à amável conversa mantida em Murcia com Maurizio Gribaudi, Giovanni Levi, Martine Segalen, Joan Bestard e Francisco Chacón, no final de 2007. Também meu agradecimento a Gabriela Mattina pelos ajustes de edição do presente artigo requeridos para esta publicação. 
novidade e hábito, estratégia e norma ${ }^{2}$. Tal tensão, sempre histórica, não somente alterou a textura dos papéis intrafamiliares, mas também a funcionalidade das relações entre a razão doméstica e as necessidades estruturais de mudança social ${ }^{3}$.

Sobre estes consensos simples nos propusemos desenvolver duas questões aparentemente ingênuas para a história de família: i) Em que sentido podemos dizer que a família tem história? e ii) Em que sentido a família europeia, inspiradora dos modelos clássicos de análise, se diferencia das do resto do mundo? Trata-se de certa necessidade de voltar aos fundamentos da história e à antropologia, duas disciplinas que contribuíram muito ao imaginário social sobre a família, de retomar seus encontros e acalmar os desvelos que geram certas confusões conceituais.

As evidências demonstradas pelas interpretações etnográficas sobre a família e o parentesco manifestam a existência de uma série de traços gerais quase universais, tais como a presença da família básica como grupo coresidencial; unidades de reprodução relativamente pequenas; bilateralidade reconhecida, inclusive no caso dos grupos de filiação de mesma linha e a existência de vínculos entre pais e filhos e em particular entre mães e filhos. Deste modo, a identidade adjudicada às famílias europeias (nuclearidade, bilateralidade e sentimentalidade), longe de ser particular, poderia ser fonte de atributos mais universais.

Diante desta perspectiva essencialista de uma unidade elementar de co-residência e procriação, o paradigma estruturalista interpretou a família

2 Críticas ao modelo de Parsons desafiaram suas afirmações sobre o isolamento da moderna família nuclear e documentaram padrões de assistência interfamiliares. ADAMS, B. Kinship in an Urban Setting. Chicago: Markhan Publishing Company, 1968. Por outro lado, desde a demografia histórica, as descobertas da preexistência do modelo familiar nuclear no momento da revolução industrial na Europa Ocidental terminaram por desvelar o caráter ideológico da perspectiva estrutural-funcionalista. LASLETT, P.; WALL, R. (Eds.). Household and Family in Past Time. New York: Cambridge University Press, 1972. BESTARD, J. Parentesco y modernidad. Barcelona: Paidós, 1998. CICERCHIA, R. Familia: Historia de una idea. In: WAINERMAN, C. (Comp.). Vivir en Familia. Buenos Aires: Losada, 1994. Do mesmo autor, (Comp.). Formas familiares, procesos históricos y cambio social en América Latina. Quito: Abyayala, 1998 b.

3 A razão doméstica é um conjunto de lógicas concorrentes na organização do grupo familiar. ANDERSON, M. Approaches in the history of the western family (1500-1914). Londres: Cambridge University Press, 1995. Também é pertinente repensar o conceito de espírito de família segundo o qual a família é uma esfera intersubjetiva que se vive como objetiva por seus membros, possibilitando sua reprodução no contexto social geral. BOURDIEU, P. Razones prácticas: sobre la teoría de la acción. Barcelona: Ediciones Anagrama, 1997. 
como um processo histórico e a família europeia como um de seus itinerários singulares. O pensamento moderno a coloca como tributária de um acontecer particular que criaria as condições de possibilidade da industrialização e à sua afinidade eletiva com a família nuclear. Forma familiar de traços que, longe de ser uma variação de caracteres universais, foram marcas particulares de um tipo de estruturas sociais ligadas ao capitalismo surgido na Europa. Assim as coisas, os demais elementos do sistema de parentesco, tão óbvios e naturais, não foram suscetíveis de um olhar crítico: não existem grupos de filiação, porque existem só famílias, as terminologias se adaptam à concepção naturalista da procriação, o incesto se define no âmbito da tríade familiar do complexo de Édipo, as concepções culturais da procriação são as que diz a ciência sobre a reprodução humana e a concepção da pessoa se rege pelo princípio individualista: um indivíduo não é uma relação, mas uma entidade autônoma e diferenciada.

Por outro lado, se propõe uma linha divisória entre família e parentesco. A família nuclear é um ente produtor de indivíduos autônomos, enquanto que o parentesco é relacional e organizador de grupos e lealdades primordiais. Diferentemente da família nuclear afiliada à modernização, os outros traços do parentesco teriam origem remota, conformando uma sucessão de patamares de continuidades. A terminologia e a ausência de grupos de filiação são de origem germânica, a definição do incesto e do casamento é de origem cristã, a concepção individualista da pessoa está relacionada com a doutrina cristã do mútuo consentimento, ou melhor, com as parentelas germânicas, onde não existem grupos, mas indivíduos relacionados, e finalmente, as doações matrimoniais são herança da tradição romana.

Essa trajetória genealógica exacerbou as perspectivas tanto históricas como antropológicas. No território da história, ao separar a família do sistema de parentesco existe uma tendência a observá-la como um traço particular da modernidade ocidental e ao sistema de parentesco como um tipo universal, próximo aos feitos naturais da procriação. Na visão antropológica, em contrapartida, o sistema de parentesco é visto como autenticamente variável e suscetível de comparação entre sociedades, enquanto que se considera a família elementar como a unidade mínima do parentesco. Em ambos os casos, trata-se desse fundamentalismo que recupera indiretamente o mito da natureza biológica do sujeito, justamente quando, graças à ciência 
e às novas tecnologias, tomamos consciência não apenas de sua progressiva perda e modificações, mas também da relação existente entre isso que se denomina biológico e a história. Como se os fatores biológico e identitário fossem pré-estabelecidos ao uso do critério funcionalista das mudanças sociais.

Ao mesmo tempo em que a teoria da modernização considerou a nação como um fenômeno político ligado aos processos de industrialização, também teve que configurar tipos tradicionais para dar-lhe particularidade e legitimidade cultural e histórica. A família nuclear, individualizada, isolada e romântica emergiu como contraparte de uma família tradicional, extensa, relacional e socialmente interessada. Para o paradigma modernista, a família nuclear e o indivíduo que esta reproduz são modernos e o parentesco, esse universo relacional centrado nos antepassados e baseado em laços naturais, é tradicional. O modernismo exigiu o abandono de amplos laços de parentesco para vislumbrar a figura de indivíduos livres, considerando o parentesco como um vínculo primordial abonado por laços contratuais e cívicos. Assim, na teoria da nacionalidade, seus membros diluem suas antigas divisões étnicas e suas lealdades para constituir voluntariamente um contrato social entre cidadão. O que resulta de todo este processo é a família nuclear e sua esfera privada, aquela que reproduz indivíduos socialmente móveis, base da sociedade civil vis à vis com a nação cívica, uma esfera pública que proporciona identidade a estes indivíduos.

Esta ideia moderna de família, profundamente arraigada em nossas representações sociais, é o principal retrato do campo das histórias pioneiras da família na Europa ${ }^{4}$ : um discurso sobre a dissolução dos laços primordiais do parentesco, o desaparecimento de grandes famílias, a aparição de uma subjetividade doméstica entre esposos individualistas e a valoração dos filhos como objetos do sentimento. Nessa narrativa, o parentesco fica situado no passado - os antepassados geram nossas relações de parentesco - e a mentalidade individualista no presente - o par conjugal gera indivíduos que vão se diferenciando de toda tradição. O dilema consistiu, para esse relato, em situar o momento de aparição do complexo familiar nuclear e estabelecer

4 Refiro-me basicamente aos trabalhos de: ARIES, P. L'enfant et la vie familiale sous l'Ancien Régime. Paris: Editions du Seuil, 1973. SHORTER, E. The Making of the Modern Family. Nueva York: Basic Books, 1975. STONE, L. The Family, Sex and Marriage in England 1500-1800. New York: Harper and Row, 1977. 
seu grau de funcionalidade com as estruturas sociais. Assim, o capitalismo, a industrialização e a modernização foram os eixos-chave que permitiram desvelar a gênesis e a configuração do complexo da família nuclear.

No entanto, o trajeto da dissolução progressiva dos laços primordiais do parentesco até chegar a laços contratuais entre indivíduos que se situam depois das relações naturais da procriação se apresenta conflituoso para um pensamento histórico preocupado pelos contextos temporais e espaciais e para aquelas perspectivas antropológicas interessadas nos processos culturais que articulam as relações de parentesco com a reprodução social. No território da história, a resposta foi uma ênfase nos processos regionais e em uma melhor conceituação da unidade doméstica ${ }^{5}$. Quer dizer, uma combinatória de elementos estruturais e culturais de maior envergadura social. No discurso antropológico, o novo olhar se orientou a certa rejeição pelas definições uniformes e universais de família, matrimônio e redes de parentesco, dando lugar a caracterizações mais contingentes abertas a contextos culturais concretos. E o matrimônio - por conveniência - entre a história e a antropologia arrojou algo de luz à hora de projetar visões menos saturadas sobre o campo: corpus estatísticos, genealogias e culturas regionais ${ }^{6}$.

Os arquivos, sobretudo europeus, foram uma cartografia eficaz à hora de ensaiar novas perspectivas de análises, assim como os fenômenos de uma contemporaneidade que delata solidão, fragmentação e pragmatismos. Existe uma revalorização do parentesco, um cosmo estruturante das relações familiares e central na configuração de redes sociais. Chave de entrada ao entendimento do matrimônio como um sistema de intercâmbios.

O método genealógico se fez popular na reconstrução das ascendências e para a observação da relação entre os sistemas de herança e

5 Foi a demografia histórica que outorgou ao estudo da família uma base quantitativa capaz de medir o impacto das transformações sociais na composição, tamanho e desenvolvimento das formas familiares. HENRY, L. Manuel de demografia historique. Geneva: Libraire Droz, 1967. FLEURY, M.; HENRY, L. Des registres paroisiaux a l'histoire de la population. Manuel de dépouillement et d'exploitation de l'état civil ancien. París: INED, 1956. Um dueto ilustre, família e povoação, eixo do debate nas décadas dos setenta e oitenta. Foi então que, a partir de um modelo de matriz estruturalista, a historiografia inglesa explorou a dinâmica entre os tipos de herança e a morfologia das unidades domésticas, sustentando suas premissas na incidência dos fatores econômicos e demográficos.

6 BJERG, M.; BOIXADOS, R. (Eds.). La familia. Campo de investigación interdisciplinario. Teorias, métodos y fuentes. Bernal: Universidad de Quilmes, 2004. 
a reprodução social. Junto às maneiras rituais das passagens, foram se recuperando os sentidos sociais profundos de condutas e valores e acedido como nunca antes a espaços importantes de subjetividade dos próprios atores: a agência.

As regiões, os povos, os lugares e cenários exclusivos da indagação antropológica foram encontrando tradução nos intentos da micro-história ${ }^{7}$. Derivado da corrente transacional, também se renovava o conceito de estratégia. Para avaliar objetivos e performances destas estratégias individuais racionais se entendeu a necessidade de reconstruir toda uma rede de relações baseadas no parentesco, nas lealdades locais e na vizinhança. A recriação de vários egos que explicavam melhor as dimensões, alcances e consistências de dita interação. Assim se aperfeiçoava um conceito essencial para o seguimento dos processos de reprodução familiar e dos princípios e normas que governam a transmissão do patrimônio ${ }^{8}$.

Em sentido inverso, a consciência de que a historicidade era um assunto de extrema importância no estudo da família resultou num pontochave para dinamizar e redirecionar o ângulo antropológico, tradicionalmente sincrônico e horizontal ${ }^{9}$.

\section{Um itinerário americano para o campo}

Os estudos sobre a família na América do Norte deram seus melhores frutos ao imaginar um tipo de relação particular entre as lógicas domésticas e o universo da industrialização e o mundo do trabalho ${ }^{10}$. Era óbvio então o papel de protagonista do parentesco na organização das

7 Reconhecemos em Le Roi Ladurie um pioneiro excepcional desta perspectiva. LADURIE, L. Montaillou, village occitan de 1294 a 1324. Paris: Gallimard, 1975. Para o espaço latino-americano o quase íntimo - e prévio - trabalho de Luis González. GONZALEZ, L. Pueblo en vilo. México: Fondo de Cultura Económica, 1968.

8 LEVI, G. La herencia inmaterial. La historia de un exorcista piamontés del siglo XVII. Madrid: Nerea, 1990.

9 SEGALEN, M. Antropología histórica de la familia. Madrid: Taurus, 1997. Press, 1982.

10 HAREVEN, T. Family Time and Industrial Time. Nueva York: Cambridge University 
migrações do campo para a cidade e como mediador do grupo doméstico frente às instituições e formas capitalistas. Entre seus aportes mais sólidos, surge a ideia de life course. Um tipo de entrada analítica que iluminou com eficácia os desenvolvimentos individuais em relação ao plano familiar e às condições históricas. Esse mundo de reciprocidades entre os projetos de vida e as metas coletivas ${ }^{11}$.

Para a América Latina, imaginamos o universo complexo e variado de formas familiares tanto na sociedade colonial quanto no período independente ${ }^{12}$. O componente étnico foi central nesse sincretismo de tradições, valores e normas no marco de mudanças profundas, desde a configuração de formações sociais mercantilistas até os desenvolvimentos propriamente capitalistas ${ }^{13}$.

Dois modelos embasaram os estudos para a região: o de Hajnal, que postulava padrões de casamento tardio para a Europa ocidental com altos índices de celibato, e o de Stone, que vinculava a aparição do individualismo afetivo à fragilidade da estrutura patriarcal e à emergência de relações sociais de índole capitalista ${ }^{14}$.

O ímpeto de tais argumentos alimentou as investigações sobre os comportamentos demográficos, sobretudo a partir do século XVIII, quando os registros são mais coerentes e consistentes. Assim, foi possível distinguir setores sociais, castas e grupos étnicos ${ }^{15}$. Mas foram as elites as que chamaram a atenção dos pesquisadores. Ricas em testemunhas, um conhecimento de base genealógico permitiu abordar a gênesis e a morfologia

11 ELDER, Jr. Children of the Great Depression: Social Change in Life Experience. Chicago: University of Chicago Press, 1974.

12 Duas balizas marcaram consideravelmente as questões a examinar na região. Trata-se dos números especiais do Journal of Family History (v. 3, n. 4, 1978; e v. 10, n. 3, 1985), dedicados à América Latina. O primeiro deles abordava a complexa trama de relações entre desenvolvimento capitalista, industrialização e parentesco na região. O segundo analisava, através de diferentes casos nacionais, o papel da família e as redes no desenvolvimento econômico durante o século XIX. Um terceiro número sobre a América Latina se ocupou das temáticas da infância na história regional. Journal of Family History, v. 23, n. 3, 1998.

13 GRUZINSKI, S.; BERNAND, C. Los hijos del Apocalipsis: la familia en Mesoamérica y en los Andes. In: BURGUIERE, A. et al. Historia de Familia. Madrid: Alianza Editorial, 1988.

14 ARROM, S. Perspectiva sobre la historia de la familia en México. In: GONZALBO AIZPURU, P. (Comp.). Familias Novohispanas, Siglos XVI al XIX. México: El Colegio de México, 1991.

15 LAVRIN, A. (Coord.). Sexualidad y matrimonio en la América hispánica. Siglos XVI-XVIII. México: Grijalbo, 1991. 
das famílias notáveis, a formação de seus patrimônios e as estratégias de conservação do poder. Heranças, redes de negócios e contatos políticos formaram o arsenal de suas políticas de reprodução social ${ }^{16}$. Deste ponto de vista, surge uma marca genuinamente autóctone: o modelo das três gerações ${ }^{17}$.

$\mathrm{Na}$ atualidade, pretensões mais holísticas dominam a produção. Trata-se de um entusiasmo bem fundado ao entender a família em sua relação com a sociedade toda, com os discursos de poder, com as configurações culturais, com as diversidades étnicas e de gênero ${ }^{18}$. São partes desse encanto da diversidade a complexidade e a flexibilidade das formas familiares ${ }^{19}$. No entanto, após tanto tempo, tais empresas, réplicas daquela grande cobertura feita pelos historiadores franceses há mais de 20 anos, cedem, uma vez mais, à potência das restrições que os sistemas nacionais impõem. Em síntese, os objetivos foram claros e os resultados, importantes. Mas, hoje, a projeção desta enorme base monográfica parece incerta. $\mathrm{O}$ discurso da interdisciplinaridade, como tantos outros desta saturada era da comunicação, tem ecos de retórica.

Senão vejamos: a história social da América Latina contemporânea é uma história de migrações e pobreza; as viagens transatlânticas da Europa e as outras, desde o campo aos povoados e cidades, desde um país a outro, abonaram processos de urbanização particulares, disparando o crescimento e hegemonia das cidades primadas; configurações sociais que tiveram um impacto central nas formas domésticas. Sabemos que para a região a migração se converteu em um fenômeno massivo a partir dos anos cinquenta, uma vez consolidadas verdadeiras redes de apoio no processo de adaptação à vida urbana. Mas ainda desconhecemos o papel das redes familiares na definição histórica destes novos padrões de deslocamento e assentamento.

16 BRADING, D. Mineros y comerciantes en el México Borbónico. México: Fondo de Cultura Económica, 1972. WOORTMANN, E. Heredeiros, parentes e compadres. San Pablo: HUCITEC, 1995.

17 BALMORI, D. et al. Notable Family Networks in Latin America. Chicago: University of Chicago Press, 1984.

18 RODRIGUEZ, P. (Coord.). La familia en Iberoamérica 1550-1980. Bogotá: Universidad Externado de Colombia, 2004.

19 CICERCHIA, R. The Charm of Family Patterns: Historical Background and Social Change in Latin America. In: DORE, E. (Ed.). Latin American Cross Currents in Gender Theory. Nueva York: Monthly Review Press, 1997. 
Os conteúdos, fluxos e alcances das redes variam segundo as classes sociais. Nos setores populares, estes contatos entre zonas de origem e destino são garantia de sobrevivência, permanência e integração. Ordenam estratégias compartilhadas que operam sobre a mesma natureza das unidades domésticas, transformando-as em um coletivo que produz zonas de encontro entre âmbitos e hábitos distantes.

Com frequência, as migrações se instalam em contextos sociais de redes clientelísticas de caráter vertical ou semisservil. Um sistema de lealdades de pobres a ricos, de mulheres a homens, criando laços de dependência que se conectam com uma cultura doméstica tradicional - e às vezes solidária - deste tipo de família ampliada. Assim, vai se estruturando uma vida cotidiana, a dos migrantes, centrada na adaptação à nova urbana - e marginal -, e na colaboração com a rede de parentes e familiares na cadeia migratória. As respostas, como as atuais ante as crises, foram complementarmente domésticas e coletivas, ou seja, identitárias. Um desafio intelectual à nossa algo obsoleta bateria de perguntas.

\section{Algumas notas sobre os arranjos residenciais e a organização social da cotidianidade}

Moradia, alimentação e vestuário constituem três regiões do consumo que as famílias enfrentam para poder reproduzir sua vida em termos cotidianos. As respostas estão caracterizadas pela diversidade histórica e cultural e os componentes sociais que determinam a qualidade do tipo de estratégias que correspondem aos intentos de satisfação. Mas, a análise sobre os consumos domésticos necessita de premissas elaboradas voltadas a buscar um maior grau de especificação. Em primeiro lugar, vestuário e moradia são diretamente observáveis, mas com atributos bem diferenciados: a primeira é móvel e a segunda, fixa. O vestuário é visível e compromete o usuário, transmitindo mensagens e identidade social; a moradia fica atrás, distante da visibilidade dos outros.

Alimentação e vestuário se consomem individualmente. O que admite diferentes graus e formas de organização coletivas. Assim, os membros do grupo doméstico podem ter acesso à comida e ao abrigo de 
variadas qualidades e realizar estes consumos em diferentes redes. E, por outro lado, diretamente ligada à organização familiar e ao grupo, à moradia. Falamos de moradia como essa construção material que abriga as atividades de um grupo doméstico, esse locus no sentido físico mais empírico em que acontecem as ações de reprodução cotidiana e produtiva: refúgio, âmbito, cenário. Um in situ de preeminências e preferências relativas nos próprios consumos habitacionais, em que prima um habitus homogêneo que só se vê alterado pelo tempo de estadia residencial de cada membro do lar.

Assim, o atributo distintivo deste consumo se encontra na estabilidade temporal do arranjo como um nível determinante da realização do plano familiar e da resolução dos obstáculos que propõem a vida cotidiana: o ponto fixo no espaço constituído pela casa ${ }^{20}$. É esta mesma permanência nos arranjos de moradia que determinará o acesso a alguns serviços públicos e incluso o ingresso ao mercado de trabalho.

Do mesmo modo, há que se considerar modificações eventuais que se relacionam com três tipos de condicionamentos. Em primeiro lugar, o ciclo de vida familiar; logo, processos de mobilidade social que impactam nos projetos residenciais; e, por último, fatores externos originados nos poderes públicos ou nas disposições de terceiras partes que obrigam a reorganização do habitat do grupo doméstico.

Existe ainda um desdobramento na aproximação à questão da moradia que dificulta uma compreensão acabada do assunto. Por um lado a perspectiva macrossocial que se monta na existência de relações de mercado ao nível da propriedade, da produção de residências e das relações de intercâmbio (assumindo que a casa popular nunca foi um mercado livre); e de uma intervenção estatal que jogou historicamente um papel central na situação habitacional dos setores populares. Por outro ângulo, o olhar intradoméstico que tende a consagrar a estratégia do esforço como a única ferramenta eficaz para o acesso ao teto. Articular estas dimensões significa, então, ter em conta como se configura cada moradia em função de suas relações com o exterior ${ }^{21}$.

É justamente a noção de serviços habitacionais que devem ser retomados na hora de envolver analiticamente a casa como unidade

20 HELLER, A. Sociología de la vida cotidiana. Barcelona: Península, 1977.

21 FEIJOO, M. Buscando un techo. Familia y vivienda popular. Buenos Aires: CEDES, 1984. 
individual com seu contexto. É o nível de equipamento social que tem um impacto decisivo nas condições de vida de cada grupo familiar. Em outras palavras, quando a provisão coletiva é deficiente, não só diminui a qualidade de cada residência, mas indica que grande parte da energia familiar deve ser aplicada na luta pelos consumos cotidianos.

O estudo das práticas contemporâneas de reprodução familiar dos setores populares na América Latina se pauta no problema mais amplo da expansão das atividades do grupo e da ocupação de terras fiscais. Houve consensos acadêmicos em remarcar a tensão entre a norma e o costume para a análise de uma variedade de estratégias que, sem estar em confronto, pelo menos em termos absolutos, com o marco jurídico liberal, conformaram material e simbolicamente traços de uma nova cultura familiar, não carente de tradições, nem violências. Medir aqui os níveis de conflito que determinam as estratégias de compensação e socialização torna-se uma questão central na hora de observar a interação das dinâmicas do "dentro" e "fora" que produzem essas reacomodações.

Mas, vamos por partes: sabemos que as atividades familiares giram ao redor da produção e consumo cotidiano de alimentos e outros bens e serviços de subsistência, assim como as tarefas relacionadas com a reposição produtora; como em toda organização, o acesso a recursos para a satisfação dessas demandas é conflitante. O grupo deve trabalhar para a obtenção ou criação de recursos, para sua administração e para sua continuidade. Esses recursos, financeiros ou não, provêm de várias fontes: do trabalho dos membros, das transferências formais do Estado, das transferências formais de organizações sociais e das transferências informais. Não pensar a correspondência entre a convivência e a distribuição de responsabilidades dificulta a compreensão dos dados sobre esta dinâmica particular do universo doméstico. Pobres são os resultados que arrojam neste arcabouço tanto os censos quanto as pesquisas domésticas. Só a investigação em profundidade poderia oferecer um diagnóstico certo sobre a magnitude e a lógica das responsabilidades familiares.

Como sabemos, uma parte importante das atividades domésticas cotidianas vincula-se às tarefas de consumo. Um verdadeiro campo de práticas sociais que requer organização, tempo e dedicação. E, como também sabemos, é reconhecido faz muito tempo (creio que desde a década de 1930) o papel dominante das mulheres nestas funções e seu rol multiplicador na 
economia. $\mathrm{O}$ aumento constante na proporção de mulheres casadas que trabalham fora do âmbito doméstico, uma maior e mais próxima autonomia juvenil e as mudanças produzidas na oferta de bens e serviços (bens industriais para o conforto doméstico, provisão de alimentos preparados e os novos formatos de atividades de tempo livre), modificou parcialmente o cenário. Com certeza, majoritariamente as mulheres são as encarregadas do trato cotidiano que organiza o consumo e a limpeza, enquanto que as disposições sobre os bens duráveis familiares estão em maior medida em mãos dos homens e, acessoriamente, nas pressões das crianças e jovens. A partir de uma perspectiva social, as práticas de consumo não só se limitam às tarefas de transformação dos bens produzidos e comercializados pelo mercado. A provisão de bens e serviços de natureza coletiva constituiu uma zona de combate pela democratização das famílias e pela incorporação de setores aos direitos da cidadania social. $\mathrm{O}$ acesso diferencial a esses bens e serviços é parte central da dinâmica de classes de toda sociedade. Em outras palavras, as práticas do consumo constituem elementos indispensáveis da configuração de hierarquias domésticas e de modelos de inclusão social.

A crise do Estado de bem-estar e as mudanças nas políticas sociais que reduziram a presença dos poderes públicos e ampliaram o caráter livre e de mercado para atividades de tipo social tiveram como efeito a "privatização" das responsabilidades familiares. Desde então, os custos destes serviços devem ser cobertos individualmente, ou por redes, ou por unidades familiares. Um processo que dramatiza a polarização social.

A conjunção de esforços e recursos define o estilo de vida da família, o que chamamos nível de bem-estar. Seu cálculo depende também da organização doméstica ao longo da vida, a partir da constituição de um novo núcleo conjugal, que é uma estratégia eficaz para incluir normas e expectativas sociais em relação com os processos de subjetivização do projeto de família. Não nos referimos às metáforas do noivado, nem às do "ninho vazio", sequer às apassivas solidões da maturidade. Abandonos, rupturas, divórcios, retornos, cessões, encaixes, migrações, constituem agora uma normalidade antitética, claro, com aquelas imaginativas suspeitas parsonianas.

Em qualquer caso, para começar, uma união; projeto comum, alguns recursos materiais e compromissos. Uma acumulação originária que inclui capital humano, social e cultural das partes, atualizado pelo mercado e o 
contrato familiar. Constelação de epifenômenos profundamente afetada pela conjuntura econômica e as políticas de Estado, entre elas e fundamental, a política de moradia. Esse lar-locus que alberga as atividades de reprodução cotidiana e gerador do grupo familiar.

Com o tempo, a estrutura doméstica irá se transformando com a adição de novos membros e a separação de outros. Transições definitivas que vão atualizando o contrato familiar. Trata-se de um conjunto de opções avaliadas ao calor das tradições culturais e o pragmatismo próprio de seus atores. Estratégias. E como um telão de fundo, a expectativa social de incremento do capital econômico ao longo dos ciclos familiares, a outra cara da ética do esforço pessoal. Aqui a centralidade da eficiência das pautas de consumo e a administração dos recursos. Questões referentes ao sistema de autoridade, controle e incentivos dentro da organização doméstica.

Existe acordo sobre a eficácia econômica do lar multipessoal. Há economias de escala tanto monetárias quanto de tempo que tornam demasiado custosa a vida solitária. No entanto, a racionalidade econômica é uma e outra vez motorizada por um conjunto de apelações morais e afetivas que lhe dão sentido. Seguimos falando das debilidades e fortalezas desse mundo "do pão e os afetos"22.

\section{Sete fundamentos, a modo de conclusão}

1. Reafirmar o caráter patriarcal e o impacto decisivo da lógica econômica do capitalismo sobre a organização familiar

O primeiro efeito do poder exclusivo dos homens, a partir do ponto e hora em que se fundou, o observamos na forma de família patriarcal ${ }^{23}$. $\mathrm{O}$ que caracteriza historicamente a família é a organização de certo número de

22 Expressão que sintetiza a busca de um tipo de subjetividade especial no desenvolvimento das dinâmicas domésticas. JELIN, E. Pan y afectos. La transformación de las familias. Buenos Aires: Fondo de Cultura Económica, 1998. [1884], 2001.

23 ENGELS, F. El origen de la familia, la propiedad privada y el estado. Madrid: Cofas, 
indivíduos, livres e não livres, em um grupo submetido ao poder paterno do chefe; seus traços essenciais são a incorporação dos forasteiros e o comando paterno; por isso, a família romana é o tipo perfeito dessa forma social. Relembremos que famulus significa escravo doméstico e a família como patrimonium (ou seja, herança), se transmitia por testamento. Em outras palavras, a invenção de um organismo cujo chefe tinha sob seu poder, a mulher, os filhos e certo número de dependentes, através da pátria potestade, e o "direito de vida e morte" sobre todos eles. Marx assinalava que a família moderna é um embrião, não só de escravidão (servitus), mas também de servidão, e ali encerrados, in miniature, todos os antagonismos que realizarse-ão mais adiante nas esferas pública e privada. Um desenvolvimento que proliferou na existência das tecnologias políticas aplicadas sobre o corpo, a saúde, a alimentação, a moradia e as condições de vida. Técnicas todas que em seu momento inaugural enquadraram sua coerência no policiamento das famílias ${ }^{24}$. A degradação da mulher convertida em um simples instrumento de reprodução foi gradualmente retocada, dissimulada e, em certos lugares, revestida de formas mais suaves. Cada progresso da produção nos mostra ao mesmo tempo um retrocesso na situação dos setores subalternos, quer dizer, da imensa maioria. Cada benefício para uns é por necessidade um prejuízo para outros; cada grau de emancipação conseguido por uma classe é um novo elemento de opressão para a outra. Pois bem, a força de trabalho na ação, o trabalho mesmo, continua sendo a atividade vital das classes populares. E, como sabemos, esta atividade vital se vende a outros para garantir os meios de vida necessários. Quer dizer, esta atividade vital não é para os trabalhadores mais que um meio para poder existir. Trabalhar para viver, energia convertida em mercadoria adjudicada a um terceiro. Sem ser o produto o fim da atividade, o que os trabalhadores produzem para si continua sendo o salário. Para eles a vida começa ali onde terminam essas atividades, na mesa de sua casa, no fogo da cozinha, na cama. Sob o domínio da produção capitalista, ainda na era pós-industrial, em que uma classe numerosa e cada vez mais extensa da população só sobrevive por meio de seu trabalho, o círculo vicioso da reprodução social não se rompeu: trabalhar e manter-se em condições de seguir trabalhando. 


\section{Revisitar a hermenêutica da "razão familiar"}

O conceito de razão doméstica é paradoxal. Trata-se dessa ideia que encerra tanto a realidade social (objetiva) na qual estão incluídas tanto a materialidade familiar quanto a realidade interindividual (subjetiva) capaz de outorgar à família essa qualidade ontológica transcendente. No entanto, herdamos conceitos parecidos do paradigma funcionalista. A diferença estaria em distanciar-se de um esquema homeostático e harmônico para pensar a família como parte de um equilíbrio conflitante: a família como sujeito da mudança social. Assim, não só reconheceríamos o habitus, mas, sobretudo, haveria um registro do campo. Desse modo, iluminaríamos a existência de relações de poder derivadas da composição diferencial do capital (econômico, social, cultural e simbólico) de cada integrante familiar, dos diferentes posicionamentos dentro deste campo e das tensões que produzem tanto a consecução como a quebra do espírito de família, esse cosmos de vivências intersubjetivas que se vivem como objetivas pela parentela, possibilitando sua reprodução.

Assim entendido, é razoável pensar o cenário familiar como um território de fronteiras, ou, o que é o mesmo, como zona de encontros. A implicância dessas categorias se radica na relevância do exercício de uma disposição dos atores ajustada às condições de possibilidade que as conjunturas manifestam. Em termos gerais, fixa-se o acontecimento à pura praticidade do que advém e reserva-se a reflexão teórica para as estruturas $^{25}$. Poderíamos pensar que é o mesmo incidente o que depende de uma construção de conceito e basicamente por dois motivos: pode-se intuílo, antecipando sua forma abstrata, e comprová-lo, trazendo-o a uma prática de intervenção, certamente, pensada. Assim, todo acontecimento é singular, expressa uma multiplicidade de situações e corresponde a uma identidade histórica. Uma ideia bastante distante da prática comum que termina por incluir em cada sucesso familiar o inventário de todos os traços e gestos que oferece uma época ou um modelo de interpretação. Nesta composição, os atores encarnam sujeitos com certas margens de improvisação em um território de definição de sentidos familiares; esse esquivo e fundamental universo das performances. 
3. Reinterpretar as práticas familiares como expressão de um sistema cultural

O simbólico possui entidade e é tangível como qualquer produção material. As estruturas que representa, certamente opacas na maioria dos casos, são realidades concretas. Os novos instrumentos devem capturar os detalhes mais localizados e o mais global das estruturas, isso sim, de maneira simultânea ${ }^{26}$. Os estudos de família necessitam posicionar-se como uma indagação interpretativa em busca de significações na direção de delinear um novo campo - e discurso - social. Um melhor escrutínio dos saberes produzidos sobre a família deve expressar-se em proposições bem estabelecidas em torno da autoridade do pater, aos ciclos familiares e seus ritos de passagem, às identidades sexuais, aos intercâmbios com as instituições sociais. Parte importante de nossa indagação deve concentrarse no que denomino a dimensão cultural da análise das formas familiares. A percepção de que a família harmoniza as ações humanas com uma ordem e projeta essa mesma ordem ao plano da experiência parece já uma verdade de Perogrullo. Apesar de tanta etnografia acumulada, carecemos de uma explicação analítica de toda essa cotidianidade; tem-se descuidado da maneira concreta, empírica, vivencial, em que esse processo se realiza. Ampliar esse marco conceitual implica definir a família como um sistema cultural que estabelece estados, motivações e vínculos profundos e duradouros, fomentando percepções e concepções de uma ordem geral de existência eficiente. Uma nova humanística ${ }^{27}$.

\section{Repensar o matrimônio e a casa própria como um problema}

As análises demográficas têm demonstrado que a taxa de casamento mantém uma correlação positiva com o nível geral de atividade econômica e também com o acesso à moradia. Isto significa que a situa-

26 GEERTZ, C. The Interpretation of Cultures. Nueva York: Basic Books, 1973.

27 As tradições historiográficas e antropológicas referidas ao mundo do Pacífico me ofereceram um ângulo novo na análise histórica como reinterpretação cultural. Dois exemplos extraordinários desta perspectiva en: SALMOND, A. The Trial of the Cannibal Dog. Captain Cook in the South Seas. Londres: Penguin, 2003. DENING, G. Beach Crossings. Voyaging Across Times, Cultures and Self. Filadelfia: University of Pennsylvania Press, 2004. 
ção habitacional afeta de maneira relativa a taxa de nupcialidade. O padrão normativo que estabelece que no momento de sua constituição os novos casais devem formar novos lares teria que ser reconsiderado na determinação do parentesco, principalmente mais nas interações existentes entre a eleição da casa própria e a fixação de determinadas estratégias de vida. Aos critérios tradicionais residenciais, tais como matrilocalidade, patrilocalidade, avuncolocalidade, entre outros, é imprescindível considerar os fenômenos de neolocalidade e co-residência e os fatores que induzem a cada alternativa. Um conjunto de investigações regionais demonstra, às vezes, as dificuldades do estabelecimento neolocal no momento de contrair matrimônio e a postergação dessa conquista para etapas mais avançadas do ciclo de vida ${ }^{28}$. Para os setores populares, a casa própria implica um tipo de planificação a meio prazo, no qual o problema habitacional está ligado a uma definição da transição matrimonial em termos de um processo que pode diagramar-se. Nestes casos, a relação pré-marital do noivado envolve uma relação de tipo contratual, que sobrepassa os laços amorosos, que sobredetermina o conjunto de lógicas conjugais. Sem dúvida, dentro das histórias das famílias populares, é necessário convocar em primeiro lugar a luta pelo teto.

\section{Compreender o desafio proposto pela norma linguística à narrativa histórica}

Reabrir a história, ou o que comumente chamamos sua reescritura, sempre foi uma questão polêmica presente em toda prática do relato histórico. Não faz muito tempo, certa desilusão com a história social tradicional abriu as portas de um ângulo de análise que enfatizou os aspectos culturais dos processos sociais. Referimos-nos à "norma linguística", um novo marco de referências teóricas que afetaria todo o discurso sobre o social ${ }^{29}$. A partir

28 Existe um conjunto de novas tendências na historiografia urbana que identifica a moradia como o espaço mínimo de análises da organização social e territorial. A partir destas premissas busca-se articular mais adequadamente as práticas de habitar, a conformação dos lares e a organização familiar em relação com os indicadores ambientais. LÓPEZ, R. (Coord.). Perfiles habitacionales y condiciones ambientales. Historia urbana de Latinoamérica, siglos XVII-XX. México: CONACYT/Instituto de Ciencias Sociales y Humanidades de la Universidad Autónoma de Puebla/Deutsches Museum, 2007.

29 SPIEGEL, G. (Ed.). Practicing History. New Directions in Historical Writing after the Linguistic Turn. Nueva York; Londres: Routledge, 2005. 
desta visão, tem-se argumentado que as "realidades" devem ser interpretadas através das normas culturais, dos discursos e das estruturas da linguagem. No centro do debate, tanto nos níveis teóricos como naqueles próprios do metier, as noções de experiência e práticas sociais, tão caras à hora de reescrever a história de família ${ }^{30}$. Para as teorias sociais e as correntes historiográficas mais próximas ao estruturalismo, a ameaça era semiótica. Haveria que, livrando-se das luvas do desafio, refocalizar as noções de causalidade, mudança, agência, subjetividade e experiência como motores da dinâmica social. Entre os resultados que mais me interessam na discussão com o "padrão" linguístico está o retorno da narrativa histórica. Tratar-se-ia de um tipo de registro que tente eliminar a divisão entre sociedade e cultura, evitar o determinismo - em parte impetrado pelos modelos explicativos causais - e o funcionalismo, e propor o cultural como estrutura e como prática. Uma formidável reentré para agentes conscientes de suas próprias vidas, que interpretam e atuam sobre as normas, as tradições, a moral e os valores. $\mathrm{O}$ que alguns chamaram de a morte do sujeito, para outros era essa possibilidade de capturar a vontade histórica dos atores por meio de conceitos como subjetividade, agência e experiência. Tratou-se da reabilitação da ideia da intencionalidade humana e suas formas de ação. Assim, a experiência doméstica funciona, mais cômoda, como uma categoria intermediária, como um território em que as forças sociais são interpretadas e manipuladas de maneira voluntária e normativa para produzir práticas materiais e simbólicas familiares criadas por seus membros.

Assim, a linguagem não seria uma criação ex nihil, mas que responde, desenha-se e modifica-se com a experiência humana, irredutível a uma só estrutura. A experiência é o sujeito da história; a linguagem, o lugar onde as coisas acontecem, uma preocupação sobre esses atos de diálogo entre categorias recebidas e contextos percebidos, entre sentidos culturais e referências práticas ${ }^{31}$. Ou seja, pensar um território de rotinas de atitudes que ofereça a possibilidade de um novo conhecimento.

30 Aqui, minha dívida aos trabalhos pioneiros de Pierre Bourdieu, Michel de Certeau e Marshall Sahlins.

31 CICERCHIA, R. Historia de la vida privada en Argentina. V. I. Buenos Aires: Troquel, 1998 a. 
6. Reorientar os novos lineamentos da pesquisa sobre os tipos e intensidades da pobreza

A sociologia e a demografia renovaram suas óticas a fim de analisar as determinações de classe, a dominação de gênero, as relações entre família e Estado, as novas formas das uniões conjugais, as cambiantes trajetórias familiares, o equilíbrio demográfico nos mercados matrimoniais, as descendências acumuladas e os tipos emergentes de família. Perguntamonos se a família europeia com tais "graus de liberdade" a respeito de seus vínculos será capaz de prover, como no passado, a mão de obra, a força de trabalho que demanda a organização econômica. Mas, na América Latina existe um problema muito mais grave: as novas morfologias familiares não são a consequência do processo de individualização, mas do aumento da pobreza, a indigência e a fragilização dos laços familiares: isso que denominamos fenômenos de dissolução e desmembramentos ${ }^{32}$. Antes de nos dobrarmos ante a funcionalidade das famílias modernas, é necessário assegurar o pão, a moradia e o projeto familiar como anseio, aspiração. Trata-se de entender os novos padrões de conduta frente à nupcialidade, à fecundidade matrimonial e extramatrimonial, ao ciclo de vida e ao planejamento familiar segundo classes sociais e regiões, e precisar o papel que cumprem as formas familiares na transmissão intergeracional da pobreza. Em outras palavras, reforçar a comunhão entre dinâmica familiar, estrutura social e dinâmica populacional.

\section{Propor uma estética das formas familiares que historie o imaginário social}

A história foi irresistível e a conhecemos. Um impostor, Arnaud du Tilh, simulando ser Martin Guerre, esposo de Bertrande de Rols. Durante três anos, Arnaud namorou a mulher, acumulou riqueza e criou filhos. Finalmente descoberto, a aparição do verdadeiro Martin frustrou, justo na antessala de uma vitória "pírrica”, essa genial e, por sua vez, vulgar simulação. Época implacável, destino seguro de forca. Referimo-nos ao drama - familiar - que

32 TORRADO, S. Historia de la familia en la Argentina moderna (1870-2000). Buenos Aires: La Flor, 2003. 
Natalie Zemon Davis reconstruiu num livro e num filme e que inspirou mais de uma obra de teatro, dois romances e até uma opereta: O retorno de Martin Guerre $^{33}$. Tratou-se de um procedimento, protocolo, digamos, estritamente histórico. Documentos (el Arrest Memorable de Jean de Coras), horas de arquivo, escrutínio, especulação, respeito pelas vozes do passado, captura de uma sensibilidade pretérita específica, polêmica e a construção de uma poética histórica. O resultado, a reinterpretação de uma história de Guerre imaginativamente concebida, argumentada com eloquência e tragicamente apelativa. $\mathrm{O}$ talento radicou, creio, em solapar o contexto histórico à mesma estrutura da saga, em convertê-lo em texto. Cada personagem familiar é um deslocamento contraditório de tradição, realismo e independência. As forças econômicas penetram e são alteradas por vontades que aceitam e desafiam as regras de um mercantilismo florescente. O mundo rural se monetariza, quebrando a cultura doméstica das vilas medievais. A verdade jurídica se constrói e reconstrói como discurso do poder. Prudência e racionalidade em tensão. Uma lição quase perdida sobre o método historiográfico, sobre a interpretação e a soberania das fontes, sobre leque de evidências legítimas para despejar os problemas históricos, sobre a forma de ler os textos, sobre o papel da reflexão e as incertezas do conhecimento social, sobre a complexidade de um cosmos familiar vivo ${ }^{34}$. Ato de reconciliação entre nosso olhar e a cena. Sensatez e sensibilidade nos atores e em nós mesmos, o público.

33 DAVIS, N. The Return of Martin Guerre. Cambridge: Harvard University Press, 1983.

34 CICERCHIA, R. Lo que vendrá. Sensatez y sentimiento: La historia cultural de la familia y la construcción social del género. In: CICERCHIA, R. (Comp.). Formas familiares, procesos históricos y cambio social en América Latina. Quito: Abyayala, 1998c. 